\title{
FAKTOR YANG BERHUBUNGAN DENGAN STATUS IBU MELAHIRKAN DI PUSKESMAS TOLINGGULA KABUPATEN GORONTALO UTARA
}

\author{
Irzal Ayuba1), Muhammad Hasan ${ }^{2)}$ \\ 1)Puskesmas Tolinggula Provinsi Gorontalo \\ 2) Wldyaiswara Balai Besar Pelatihan Kesehatan Makassar
}

irzal.ayuba@gmail.com

\begin{abstract}
Age factor has a close influence related to the development of female reproductive devices, where the healthy reproductive age for a woman giving birth is 25-35 years of age, high parity status, the number of children more than three can affect the health status of the mother. The distance of pregnancy is the time from the pregnant woman until the occurrence of the next pregnancy, the distance of pregnancy that is too close increases the risk of pregnant women. The purpose of this study was to know the Factors with the Status of Mothers Giving Birth in the Midwifery Section of the Tolinggula Health Center, North Gorontalo Regency. Research method using Cross Sectional Study Design. That is a research plan to see if there is a relationship between the age of the mother, the number of childbirth (Parity), and the distance of pregnancy. Sampling using Purposive Sampling with Chi-Square test. Sample of 298 Respondents. The results of the study there is a relationship between the age of the mother, the number of childbirth (Parity), and the distance of pregnancy with a value of $p: 0.000<0.005$. The conclusion in the study is that there is a relationship between maternal age factor, number of childbirth (Parity), and distance of pregnancy with the status of the mother giving birth.
\end{abstract}

Keywords: Pregnancy Distance, Midwifery, Parity, Maternal Status, Age

\section{ABSTRAK}

Faktor umur mempunyai pengaruh yang erat kaitannya dengan perkembangan alat-alat reproduksi wanita, dimana umur reproduksi sehat bagi seorang wanita melahirkan adalah umur 25-35 tahun, status paritas yang tinggi, jumlah anak yang lebih dari tiga dapat mempengaruhi status kesehatan ibu. Jarak kehamilan adalah waktu sejak ibu hamil sampai terjadinya kehamilan berikutnya, jarak kehamilan yang terlalu dekat meningkatkan risiko ibu hamil. Tujuan penelitian ini adalah mengetahui Faktor-Faktor dengan Status Ibu Melahirkan dibagian Kebidanan Puskesmas Tolinggula Kabupaten Gorontalo Utara. Metode penelitian dengan menggunakan desain Penelitian Cross Sectional Study. Yaitu suatu rancangan penelitian untuk melihat apakah ada hubungan antara umur ibu, jumlah melahirkan (Paritas), dan jarak kehamilan. Pengambilan sampel menggunakan Purposive Sampling dengan uji Chi-Square. Sampel 298 Responden. Hasil penelitian ada hubungan antara umur ibu, jumlah melahirkan (Paritas), dan jarak kehamilan dengan nilai $p$ : $0,000<0,005$. Kesimpulan dalam penelitian adalah ada hubungan antara faktor umur ibu, jumlah melahirkan (Paritas), dan jarak kehamilan dengan status ibu melahirkan.

Kata Kunci : Jarak Kehamilan, Kebidanan, Paritas, Status Ibu Melahirkan, Umur

\section{PENDAHULUAN}

Setiap tahun di seluruh dunia diperkirakan terjadi 4,3 juta kelahiran mati dan 3,3 juta kelahiran neonatal. Angka tersebut dihitung dalam kondisi sekitar $40 \%$ kasus yang tidak dilaporkan. Meskipun sampai kini angka kematian bayi di berbagai negara telah mengalami penurunan, namun konstribusi kematian neonatal pada kematian bayi semakin tinggi. Kondisi tersebut dialami oleh hampir setiap negara di dunia. Langkah maju mengendalikan masalah kematian bayi telah memperlihatkan hasil yang menggembirakan. WHO memperkirakan di negara berkembang lebih dari 9 juta bayi meninggal sebelum lahir atau pada minggu pertama kehidupannya (periode perinatal), setiap tahunnya. Angka kematian perinatal $($ Perinatal Mortality Rate $=$ PMR) di negara berkembang sebesar 50 per 1000 yakni lima kali lebih tinggi daripada negara maju 10 per 1000 (Prameswari, 2007).

Wanita hamil mempunyai risiko komplikasi apalagi bagi kelompok wanita risiko tinggi yaitu wanita dengan keadaan 4T; kehamilan yang terjadi pada usia terlalu muda, usia terlalu tua, selang kelahiran terlalu dekat dan urutan anak $>3$. Kategori wanita risiko tinggi ini mempunyai risiko lebih besar untuk terjadi komplikasi dibanding kategori lain. Wanita yang tidak hamil tidak mempunyai risiko tersebut (Tin Afifah, 2004).

Angka Kematian lbu (AKI) di Indonesia tahun 2007 yaitu 262 per 100.000 kelahiran hidup. Target yang diharapkan dapat dicapai pada tahun 2010 adalah angka kematian ibu menjadi 125 per 100.000 kelahiran hidup melalui pelaksanaan MPS (Making Pregnancy Safer) dengan salah satu pesan kunci yaitu 
setiap melahirkan ditolong oleh tenaga kesehatan terlatih (Okanegara, 2008).

Tahun ini di Indonesia diperkirakan 15.000 ibu bersalin dan 100.000 bayi baru lahir akan meninggal. Namun dengan adanya melahirkan yang ditolong oleh tenaga kesehatan terlatih mencapai sedikitnya $85 \%$, dan penerapan aksi melalui perencanaan, melahirkan dan pencegahan komplikasi (P4K) di setiap komunitas, diperkirakan 6000 nyawa ibu bersalin dan 19.000 bayi baru lahir setiap tahunnya dapat diselamatkan (YPHA, 2007).

Data bagian kebidanan Puskesmas Tolinggula Januari-Desember tahun 2017 terdapat 1317 jumlah kunjungan rawat inap.

Faktor umur mempunyai pengaruh yang erat kaitannya dengan perkembangan alat-alat reproduksi wanita, dimana umur reproduksi sehat bagi seorang wanita melahirkan adalah umur 25-35 tahun. Umur ibu yang terlalu tua atau terlalu muda mempunyai kemungkinan yang lebih besar melahirkan bayi yang kurang sehat, karena ibu yang hamil pada umur kurang dari 20 tahun, dari segi biologis perkembangan reproduksinya belum optimal, dari segi sosial ekonomi belum siap mandiri dan dari segi medis sering mendapatkan gangguan kesehatan, mudah mengalami abortus, pendarahan dalam kehamilan, lahir prematur, kematian janin dalam kandungan, meninggal saat melahirkan dan melahirkan bayi dengan BBLR.

Pada umur 35 tahun ke atas, elestisitas otot-otot panggul dan sekitarnya serta alat-alat reproduksi pada umumnya telah mengalami kemunduran sehingga dapat berisiko terhadap kejadian BBLR, mempersulit melahirkan dan selanjutnya dapat menyebabkan kematian ibu dan kematian bayi.

Status paritas yang tinggi, jumlah anak yang lebih dari tiga dapat mempengaruhi status kesehatan ibu. Ibu dengan paritas tinggi cenderung mengalami komplikasi dalam kehamilan, hal ini dapat dijelaskan bahwa setiap kehamilan akan menyebabkan kelainan pada uterus sehingga pada kehamilan yang berulangulang dapat mengalami kerusakan pembuluh darah dinding uterus yang akan mempengaruhi sirkulasi nutrisi ke janin sehingga jumlah nutrisi akan menyebabkan gangguan pertumbuhan janin yang berujung pada lahir dengan berat badan lahir rendah.
Melahirkan kedua dan ketiga merupakan keadaan yang relatif aman untuk melahirkan pada masa reproduktif, karena pada melahirkan tesebut keadaan patologis dimana dinding uterus belum banyak mengalami perubahan, sedangkan pada melahirkan lebih dari empat kali dapat menyebabkan risiko yaitu kerusakan pembuluh darah dinding uterus.

Jarak kehamilan adalah waktu sejak ibu hamil sampai terjadinya kehamilan berikutnya. Jarak kehamilan yang terlalu dekat meningkatkan risiko ibu bagi hamil. Hal ini dikarenakan setelah melahirkan rahim memerlukan waktu yang cukup lama untuk pemulihan sebelum terisi lagi oleh janin, sebab pada waktu melahirkan pembuluh darah pada dinding rahim rusak sehingga mempengaruhi sirkulasi makanan ke janin. Kehamilan yang berulang menyebabkan keadaan rahim tidak sehat lagi untuk kehamilan berikutnya pada jarak waktu berdekatan. Seorang ibu memerlukan waktu dua sampai tiga tahun antara kehamilan agar pulih secara fisiologi dari melahirkan dan mempersiapkan diri untuk hamil berikutnya.

\section{METODE PENELITIAN Desain Penelitian}

Jenis penelitian yang digunakan pada penelitian ini adalah observasional analitik dengan rancangan Cross Sectional Study, yaitu suatu rancangan penelitian untuk melihat apakah ada hubungan antara Umur Ibu, Jumlah Melahirkan (Paritas) dan Jarak Kehamilan. Populasi dalam penelitian ini adalah ibu melahirkan dibagian kebidanan Puskesmas Tolinggula. Sampel dalam penelitian ini 298 responden.

\section{Lokasi Penelitian}

Lokasi penelitian adalah Puskesmas Tolinggula Kabupaten Gorontalo Utara

\section{Waktu Penelitian}

Waktu penelitian pada tanggal 25 Maret - 30 April 2017.

Teknik pengumpulan data dalam penelirtian ini adalah dengan menggunakan Observasional Analitik. Dengan rancangan Cross Sectional Study menggunakan uji statistic chi-square dengan tingkat kemaknaan $95 \%(\alpha=0,05)$ 
Hasil Penelitian

Karakteristik Responden

Tabel 1. Distribusi Responden berdasarkan Pendidikan di Bagian Kebidanan Puskesmas Tolinggula. Kabupaten Gorontalo Utara. Tahun 2017.

\begin{tabular}{clc}
\hline Pendidikan Ibu & $\mathbf{n}$ & \% \\
\hline SD & 161 & 54,02 \\
SLTP & 46 & 15,44 \\
SLTA & 63 & 21,14 \\
PT & 28 & 9,4 \\
\hline Total & $\mathbf{2 9 8}$ & $\mathbf{1 0 0}$ \\
\hline
\end{tabular}

Sumber : Data Primer

Tabel 2. Distribusi Responden berdasarkan Pendidikan Suami di Bagian Kebidanan Puskesmas Tolinggula Kabupaten Gorontalo UtaraTahun 2017.

\begin{tabular}{crr}
\hline Pendidikan Suami & $\mathbf{n}$ & $\%$ \\
\hline SD & 162 & 54,4 \\
SLTP & 45 & 15,1 \\
SLTA & 68 & 22,8 \\
PT & 23 & 7,7 \\
\hline Total & $\mathbf{2 9 8}$ & $\mathbf{1 0 0}$ \\
\hline Sumber : Data Primer & &
\end{tabular}

Tabel3. Distribusi Responden berdasarkan Pekerjaan di Bagian Kebidanan Puskesmas Tolinggula Kabupaten Gorontalo Tahun 2017.

\begin{tabular}{ccc}
\hline $\begin{array}{c}\text { Pekerjaan } \\
\text { lbu }\end{array}$ & $\mathbf{n}$ & $\%$ \\
\hline URT & 251 & 84,2 \\
Swasta & 5 & 1,7 \\
PNS & 42 & 14,1 \\
\hline Total & $\mathbf{2 9 8}$ & $\mathbf{1 0 0}$ \\
\hline
\end{tabular}

Sumber : Data Primer
Tabel 4.Distribusi Responden berdasarkan Pekerjaan Suami di Bagian Kebidanan Puskesmas Tolinggula Kabupaten Gorontalo UtaraTahun 2017.

\begin{tabular}{ccc}
\hline Pekerjaan Suami & $\mathbf{n}$ & $\%$ \\
\hline Swasta & 96 & 32,2 \\
Petani & 151 & 50,7 \\
Nelayan & 7 & 2,3 \\
PNS & 36 & 12,1 \\
TNI/Polri & 8 & 2,7 \\
\hline Total & $\mathbf{2 9 8}$ & $\mathbf{1 0 0}$ \\
\hline
\end{tabular}

Sumber : Data Primer

Analisis Univariat

Tabel 5.Distribusi Responden berdasarkan Status Melahirkan di Bagian Kebidanan Puskesmas Tolinggula Kabupaten Gorontalo UtaraTahun 2017.

\begin{tabular}{ccc}
\hline Melahirkan & $\mathbf{n}$ & $\%$ \\
\hline Normal & 217 & 72,8 \\
Risiko Tinggi & 81 & 27,2 \\
\hline Total & 298 & 100 \\
\hline
\end{tabular}

Sumber : Data Primer

Tabel 6.Distribusi Responden berdasarkan Umur di Bagian Kebidanan Puskesmas Tolinggula Kabupaten Gorontalo UtaraTahun 2017.

\begin{tabular}{ccc}
\hline Umur Ibu & $\mathbf{N}$ & $\%$ \\
\hline$<20$ tahun & 2 & 0,7 \\
20-35 tahun & 196 & 65,8 \\
$>$ 35 tahun & 100 & 33,5 \\
\hline Total & $\mathbf{2 9 8}$ & $\mathbf{1 0 0}$ \\
\hline
\end{tabular}

Sumber : Data Primer 
Tabel 7.Distribusi Responden berdasarkan Paritas Bagian Kebidanan Puskesmas Tolinggula Kabupaten Gorontalo UtaraTahun 2017.

\begin{tabular}{ccc}
\hline Paritas & $\mathbf{n}$ & $\%$ \\
\hline$>3$ kali & 98 & 32,9 \\
$\leq 3$ kali & 200 & 67,1 \\
\hline Total & $\mathbf{2 9 8}$ & $\mathbf{1 0 0}$ \\
\hline
\end{tabular}

Sumber : Data Primer
Tabel 8. Distribusi Responden berdasarkan Jarak Kehamilan di Bagian Kebidanan Puskesmas Tolinggula Kabupaten Gorontalo UtaraTahun 2017.

\begin{tabular}{ccc}
\hline Jarak Kehamilan & $\mathbf{N}$ & $\%$ \\
\hline$<24$ bulan & 113 & 37,9 \\
$\geq 24$ bulan & 185 & 62,1 \\
\hline Total & $\mathbf{2 9 8}$ & $\mathbf{1 0 0}$ \\
\hline
\end{tabular}

Sumber : Data Primer

\section{Analisis Bivariat}

Tabel 9. Hubungan Umur Ibu dengan Status Melahirkan di Bagian Kebidanan Puskesmas Tolinggula Kabupaten Gorontalo UtaraTahun 2017.

\begin{tabular}{|c|c|c|c|c|c|c|c|c|}
\hline \multirow{3}{*}{ Umur lbu } & \multicolumn{4}{|c|}{ Melahirkan } & \multirow{2}{*}{\multicolumn{2}{|c|}{ Jumlah }} & \multirow{3}{*}{$\begin{array}{c}X^{2} \\
\text { Hitung } \\
\text { p Value } \\
\text { Phi }\end{array}$} & \multirow{3}{*}{$x^{2}$ tabel } \\
\hline & \multicolumn{2}{|c|}{$\begin{array}{l}\text { Risiko } \\
\text { tinggi }\end{array}$} & \multicolumn{2}{|c|}{ Normal } & & & & \\
\hline & $\mathbf{n}$ & $\%$ & $\mathbf{n}$ & $\%$ & $\mathbf{n}$ & $\%$ & & \\
\hline$<20$ dan $>35$ thn & 41 & 40,2 & 61 & 59,8 & 102 & 100 & 13,272 & \\
\hline $20-35$ thn & 40 & 20,4 & 156 & 79,6 & 196 & 100 & $\begin{array}{l}0,000 \\
0,211\end{array}$ & 3,84 \\
\hline Total & 81 & 27,2 & 217 & 72,8 & 298 & 100 & & \\
\hline
\end{tabular}

Tabel 9 menunjukkan bahwa dari 102 responden dengan umur $<20$ tahun dan $>35$ tahun dengan status ibu melahirkan risiko tinggi sebanyak 41 atau $40,2 \%$ dan normal sebanyak 61 atau $59,8 \%$, sedangkan dari 196 responden dengan umur 20-35 dengan status melahirkan risiko tinggi sebanyak 40 atau $20,4 \%$ dan normal sebanyak 156 atau $79,6 \%$.

Hasil uji statistik menggunakan uji Chi Square diperoleh $X^{2}$ Hitung $=13,272>X^{2}$ tabel $=3,84$ dengan nilai $p=0,000<\alpha=0,05$, yang berarti ada hubungan yang signifikan antara umur dengan status ibu melahirkan di Bagian Kebidanan Puskesmas Tolinggula Kabupaten Gorontalo UtaraTahun 2017 Uji kekuatan hubungan dengan menggunakan koefisien Phi diperoleh nilai $P h i=0,211$ yang berarti hubungan antara umur dengan status ibu melahirkan bersifat lemah.

Tabel 10. Hubungan Paritas dengan Status Ibu Melahirkan di Bagian Kebidanan Puskesmas Tolinggula Kabupaten Gorontalo UtaraTahun 2017.

\begin{tabular}{|c|c|c|c|c|c|c|c|c|}
\hline \multirow{3}{*}{ Paritas } & \multicolumn{4}{|c|}{ Melahirkan } & \multirow{2}{*}{\multicolumn{2}{|c|}{ Jumlah }} & \multirow{3}{*}{$\begin{array}{c}X^{2} \\
\text { Hitung } \\
\text { p Value } \\
\text { Phi }\end{array}$} & \multirow{3}{*}{$X^{2}$ tabel } \\
\hline & \multicolumn{2}{|c|}{ Risiko tinggi } & \multicolumn{2}{|c|}{ Normal } & & & & \\
\hline & $\mathbf{n}$ & $\%$ & $\mathrm{n}$ & $\%$ & $\mathbf{n}$ & $\%$ & & \\
\hline > 3 kali & 34 & 34,7 & 64 & 65,3 & 98 & 100 & \multirow{3}{*}{$\begin{array}{l}4,164 \\
0,041 \\
0,118\end{array}$} & \multirow{3}{*}{3,84} \\
\hline$\leq 3$ kali & 47 & 23,5 & 153 & 76,5 & 200 & 100 & & \\
\hline Total & 81 & 27,2 & 217 & 72,8 & 298 & 100 & & \\
\hline
\end{tabular}

Tabel 10 menunjukkan bahwa dari 98 responden dengan paritas $>3$ kali dengan 
status melahirkan risiko tinggi sebanyak 34 atau $34,7 \%$ dan normal sebanyak 64 atau $65,3 \%$, sedangkan dari 200 responden dengan paritas $\leq 3$ kali dengan status melahirkan risiko tinggi sebanyak 47 atau $23,5 \%$ dan normal sebanyak 153 atau $76,5 \%$.

Hasil uji statistik menggunakan uji Chi Square diperoleh $X^{2}$ Hitung $=4,164 \quad>X^{2}$ tabel $=3,84$ dengan nilai $p=0,041<\alpha=0,05$, yang berarti ada hubungan yang signifikan antara paritas dengan status ibu melahirkan di Bagian Kebidanan Puskesmas Tolinggula Tahun 2017. Uji kekuatan hubungan dengan menggunakan koefisien $P h i$ diperoleh nilai $P h i=0,118$ yang berarti hubungan antara paritas dengan status ibu melahirkan bersifat lemah.

Tabel 11. Hubungan Jarak Kehamilan dengan Status Ibu Melahirkan di Bagian Kebidanan Puskesmas Tolinggula Kabupaten Gorontalo UtaraTahun 2017.

\begin{tabular}{|c|c|c|c|c|c|c|c|c|}
\hline \multirow{3}{*}{ Jarak Kehamilan } & \multicolumn{4}{|c|}{ Melahirkan } & \multirow{2}{*}{\multicolumn{2}{|c|}{ Jumlah }} & \multirow{3}{*}{$\begin{array}{c}X^{2} \\
\text { Hitung } \\
\text { p Value } \\
\text { Phi }\end{array}$} & \multirow{3}{*}{$\underset{\text { tabel }}{X^{2}}$} \\
\hline & \multicolumn{2}{|c|}{ Risiko tinggi } & \multicolumn{2}{|c|}{ Normal } & & & & \\
\hline & $\mathbf{n}$ & $\%$ & $\mathbf{n}$ & $\%$ & $\mathbf{n}$ & $\%$ & & \\
\hline$<24$ bulan & 39 & 34,5 & 74 & 65,5 & 113 & 100 & 1914 & \\
\hline$\geq 24$ bulan & 42 & 22,7 & 143 & 77,3 & 185 & 100 & 0,026 & 3,84 \\
\hline Total & 81 & 27,2 & 217 & 72,8 & 298 & 100 & & \\
\hline
\end{tabular}

Tabel 11 menunjukkan bahwa dari 113 responden dengan jarak kehamilan $<24$ bulan dengan status melahirkan risiko tinggi sebanyak 39 atau $34,5 \%$ dan normal sebanyak 74 atau $65,5 \%$, sedangkan dari 185 responden dengan jarak kehamilan $\geq 24$ bulan dengan status melahirkan risiko tinggi sebanyak 42 atau $22,7 \%$ dan normal sebanyak 185 atau $77,3 \%$.

Hasil uji statistik menggunakan uji Chi Square diperoleh $X^{2}$ Hitung $=4,944>X^{2}$ tabel $=3,84$ dengan nilai $p=0,026<\alpha=0,05$, yang berarti ada hubungan yang signifikan antara jarak kehamilan dengan status ibu melahirkan di Bagian Kebidanan Puskesmas Tolinggula Tahun 2017. Uji kekuatan hubungan dengan menggunakan koefisien $P h i$ diperoleh nilai $P h i=0,129$ yang berarti hubungan antara jarak kehamilan dengan status ibu melahirkan bersifat lemah.

\section{Pembahasan}

Hasil uji statistik menggunakan uji Chi Square diperoleh $x^{2}$ Hitung $=13,272>X^{2}$ tabel $=3,84$ dengan nilai $p=0,000<\alpha=0,05$, yang berarti ada hubungan yang signifikan antara umur dengan status ibu melahirkan di Bagian Kebidanan Puskesmas Tolinggula Kabupaten Gorontalo Tahun 2017. Hal ini sesuai dengan hasil penelitian yang dilakukan Budi Santoso, 2008 tentang hubungan antara umur, paritas, jarak kehamilan dan riwayat obsterti, dengan terjadinya plasenta previa. Mendapatkan hubungan yang bermakna antara umur, usia kehamilan dan letak anak dengan terjadinya plasenta previa.
Hasil uji statistik menggunakan uji Chi Square diperoleh $X^{2}$ Hitung $=4,164>X^{2}$ tabel $=3,84$ dengan nilai $p=0,041<\alpha=0,05$, yang berarti ada hubungan yang signifikan antara paritas dengan status ibu melahirkan di Bagian Kebidanan Puskesmas Tolinggula Kabupaten Gorontalo UtaraTahun 2017. Hal ini sesuai dengan hasil penelitian yang dilakukan oleh Budi Santoso, 2008 tentang hubungan antara umur, paritas, jarak kehamilan dan riwayat obsterti, dengan terjadinya plasenta previa menyatakan bahwa semakin tinggi paritas maka kemungkinan untuk mendapatkan plaseta previa semakin besar $(5,17)$ hubungan antara paritas dengan plasenta previa, setelah dilakukan uji statistik ternyata didapatkan OR untuk multipara 1,28 dengan interval kepercayaan 0,87-1,89 yang artinya bahwa kehamilan multipara mempunyai risiko 1,28 kali untuk terjadinya plasenta previa, demikian pula pada grandemultipara didapatkan OR $(95 \% \mathrm{Cl})$ $1,43 \quad(0,77-2,67)$, dan secara perhitungan satistik terdapat hubungan yang bermakna.

Hasil uji statistik menggunakan uji Chi Square diperoleh $X^{2}$ Hitung $=4,944>X^{2}$ tabel $=3,84$ dengan nilai $p=0,026<\alpha=0,05$, yang berarti ada hubungan yang signifikan antara jarak kehamilan dengan status ibu melahirkan di Bagian Kebidanan Puskesmas Tolinggula Kabupaten Gorontalo UtaraTahun 2017. Hal ini sesuai dengan hasil Penelitian yang dilakukan oleh Suryani tentang hubungan karakteristik ibu bersalin dan antenatal care dengan perdarahan pasca persalinan di rumah sakit umum $d r$. pirngadi tahun 2007 menunjukkan bahwa ada 
hubungan paritas $(\mathrm{p}=0,002, \mathrm{OR}=3,571)$, jarak antar kelahiran ( $P=0,006, O R=3,143)$, riwayat persalinan ( $P=0,000, O R=5,165)$, dan kunjungan antenatal $(P=0,000, O R=$ $6,000)$ dengan perdarahan pasca persalinan, sedangkan umur, pendidikan dan anemia tidak ada hubungan.

\section{PENUTUP}

\section{Simpulan}

Hasil penelitian tentang Faktor-faktor Yang Berhubungan Dengan Status Ibu Melahirkan di Bagian Kebidanan Puskesmas Tolinggula Kabupaten Gorontalo Tahun 2017, dapat diperoleh kesimpulan sebagai berikut :

1. Ada hubungan yang signifikan antara umur dengan status ibu melahirkan di Bagian Kebidanan Puskesmas Tolinggula Kabupaten Gorontalo UtaraTahun 2017.

2. Ada hubungan yang signifikan antara paritas dengan status ibu melahirkan di Bagian Kebidanan Puskesmas Tolinggula Kabupaten Gorontalo Utara Tahun 2017.

3. Ada hubungan yang signifikan antara jarak kehamilan dengan status ibu melahirkan di Bagian Kebidanan Puskesmas Tolinggula Kabupaten Gorontalo Tahun 2017.

\section{Saran}

1. Perlunya promosi kesehatan di bidang KIA (Kesehatan Ibu dan Anak) dalam upaya sosialisai secara berkesinambungan kepada ibu khususnya pasangan usia subur sehingga mengetahui pentingnya melahirkan pada umur risiko rendah.

2. Perlunya pembatasan jumlah kelahiran dengan mengikuti program KB untuk mengurangi risiko pada saat melahirkan.

3. Perlunya menjaga jarak kehamilan $\geq 24$ bulan dengan kehamilan berikutnya agar ibu lebih siap baik secara psikologis maupun fisik terutama sistem reproduksinya.

\section{DAFTAR PUSTAKA}

Azwar, Azrul. 2003. Metodologi Penelitian Kedokteran dan Kesehatan Masyarakat. Jakarta Barat : Binarupa Aksara.

Budijanto,Didik., Astuti, Dwi, dan Ismono, Hadi. 2000. Risiko Terjadinya BBLR Di Puskesmas Balerejo Kabupaten Madiun. http://eprints.ums.ac.id/ 500/1/3. Mutalazimah.pdf. Diakses 23 Februari 2009.

Binarti Oktasia,Tahun 1999-2001. Hubungan antara anemia, paritas dan penolong persalinan dengan kejadian retensio plasenta di rsup $d r$. mohammad hoesin palembang Perpustakaan: Universitas Indonesia http://www.digilib.ui.ac.id/opac/theme s/libri2/detail.jsp?id=72167\&lokasi=lo kal.

Budi Santoso, 2008. Hubungan antara Umur Ibu, Paritas, Jarak Kehamilan dan Riwayat Obstetri, dengan Terjadinya Plasenta Previa. http://drbudisantosospog.blogspot.com/2008/04/hubunga n-antara-umur-ibu-paritas-jarak.html diakses 13 juni.

Depkes RI. 1997. Kurikulum Pelatihan Dukun. Direktorat Jendral Pembinaan Kesehatan Masyarakat, Direktorat Bina Kesehatan Keluarga. Jakarta : Bakti Husada.

Depkes RI, 2001, Buku Pedoman Pengenalan Tanda Bahaya Pada Kehamilan, Persalina dan Nifas, Jakarta.

Erlina, Ditulis pada Oktober 23, 2008 Kehamilan Risiko Tinggi. http://kuliahbidan.wordpress.com/200 8/10/23/ibu-hamil-dengan-risikotinggi/ di akses 28 Februari 2009.

Gandus, 2008. Ketuban pecah sebelum waktunya http://gandusblogspot.com diakses 28 Februari 2009.

Mariani, Siti.2007. Beberapa Faktor Yang Mempengaruhi Keluarga Dalam Pemilihan Penolong Melahirkan Di Desa Kujangsari Kecamatan Langensari Kota Banjar. http://banjarjabar.go.id diakses 27 Oktober 2007.

Mulidah, Siti, Djaswadi dan Mubasisyir, 2003. "Hubungan Antara Kelengkapan Pelaksanaan Deteksi Risiko Tinggi dengan Melahirkan Lama di Kabupaten Purworejo, http://ridwanamiruddin.wordpress. com/2007/05/31/faktor-risiko-partuslama-di-rsia-siti-fatimah-makassar/ 28 Februari 2009.

Notoatmodjo, Soekidjo. 2005. Metodologi Penelitian Kesehatan. Jakarta : PT Rineka Cipta.

Okanegara, 2008., Penanganan Kegawatdaruratan Obstetri Di Tingkat Pelayanan Dasar, Jakarta. Diakses 27 Oktober 2007.

Prameswari, Meidy P. 2007. Kematian Perinatal di Indonesia Tahun 19972003 dan Faktor yang Berhubungan. Jurnal Kesehatan Masyarakat Nasional Vol 1. No 4, Februari 2007. 
Riduwan. 2003. Dasar-Dasar Statistika. Bandung : Penerbit Alfabeta

Sarwono Prawirohardjo, 2002., 2007. IImu Kebidanan. Jakarta : Tridasa Printer. http://id.wikipedia.org/wiki/Gugur kandungan Diakses 28 Februari 2009.

Setyowati, Titik. 1996. Faktor-faktor yang Mempengaruhi Bayi Lahir dengan Berat Badan Rendah (Analisa data SDKI 1994).

Suheimi, 2007. Perdarahan Ante Jartum Jakarta.http://ksuheimi.blogspot.com 2007/09/perdarahan-ante-partum. html Diakses 28 februari 2009.

Suryani, 2007. Hubungan Karakteristik lbu Bersalin dan Antenatal Care dengan Perdarahan Pasca Persalinan google. Master Theses / Public Health / Epidemiologi. USU e-Repository (c) 2008.Official Website | Site Map.
Sugiyono. 2004. Statitika Untuk Penelitian. Bandung : Alfabeta.

Suprapto, Agus. 2002. Pola Pertolongan Melahirkan 5 Tahun Terakhir.

Hubungannya dengan Faktor Sosial Ekonomi di Indonesia. http://digilib.litbang.depkes.go.id Diakses 2 November 2007.

Tin Afifah dkk, "Analisis Lanjut SDKI 20022003 Pemetaan Wanita Risiko Tinggi (4T) dengan Menggunakan Metoda SIG", BKKBN, 2004.

WHO. 2003. Pedoman praktis safe motherhood, Perawatan Dalam Kelahiran Normal. Jakarta : Penerbit Buku Kedokteran EGC.

YPHA. 2007. 100.000 Anak Baru Lahir Meninggal. http://www.ypha.or.id/ Diakses 27 oktober 2007. 